\title{
Synthetic photoswitchable neurotransmitters based on bridged azobenzenes
}

\author{
${\text { Gisela Cabréa }{ }^{\mathrm{a}}, \text { Aida Garrido-Charles }}^{\mathrm{b}, \$}$, Àngels González-Lafont ${ }^{\mathrm{a}, \mathrm{c}}$, Widukind Moormann ${ }^{\mathrm{d}}$, Daniel \\ Langbehn $^{\mathrm{d}}$, David Egea ${ }^{\mathrm{a}}$, José M. Lluch ${ }^{\mathrm{a}, \mathrm{c}}$, Rainer Herges ${ }^{\mathrm{d}}$, Ramon Alibés ${ }^{\mathrm{a}}$, Félix Busquéa ${ }^{\mathrm{a}}$, Pau \\ Gorostiza $^{\mathrm{b}, \mathrm{e}, \mathrm{f}, *}$ and Jordi Hernando ${ }^{\mathrm{a}, *}$ \\ ${ }^{a}$ Departament de Química, Universitat Autònoma de Barcelona (UAB), Cerdanyola del Vallès, Spain. \\ ${ }^{\mathrm{b}}$ Institut de Bioenginyeria de Catalunya (IBEC), Barcelona Institute of Science and Technology (BIST), Barcelona, Spain. \\ ${ }^{\mathrm{c}}$ Institut de Biotecnologia i de Biomedicina (IBB), UAB, Cerdanyola del Vallès, Spain. \\ d Otto Diels-Institute of Organic Chemistry, Christian Albrechts University Kiel, Kiel, Germany.

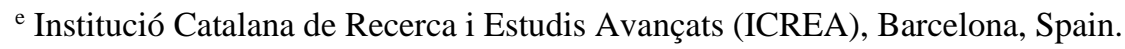 \\ ${ }^{\mathrm{f}}$ Centro de Investigación Biomédica en Red en Bioingeniería, Biomateriales y Nanomedicina, Zaragoza, Spain.
}

Supporting Information Placeholder

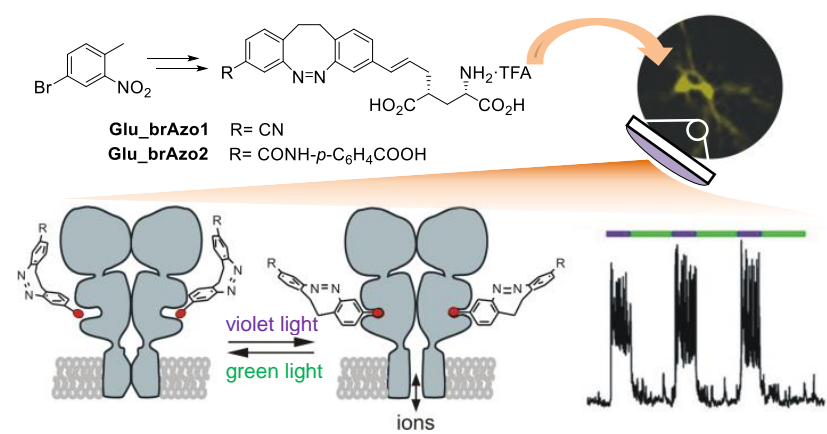

By enabling remote manipulation of neuronal signaling with light, optogenetics ${ }^{1}$ and photopharmacology ${ }^{2}$ have revolutionized neuroscience and neurobiology. Neural receptors responding to glutamate (GluRs), the primary excitatory neurotransmitter, are one of the major targets in these fields, since they regulate several key processes in the nervous system and are related to numerous diseases. ${ }^{3}$ As such, a plethora of photopharmacological tools have been developed for light-gating GluRs ${ }^{4}$ among which photochromic ligands (PCLs) ${ }^{5-12}$ are often preferred because they combine (a) the advantages of small-molecule, freely diffusing drugs with (b) the capacity for reversibly photoswitching their activity without by-product generation nor modification of native receptors. $2^{, 4}$

The major strategy employed to derive PCLs relies on introducing an azoaromatic photoswitch into the structure of wellknown, biologically-active ligands. $2^{4}$ Upon trans-cis photoisomerization, ${ }^{13}$ a geometrical change is induced in these compounds that alters their interaction with the receptor. Typically, the more extended configuration of the trans isomer favors such interaction, while affinity is reduced for the folded cis state due to steric effects (i.e. trans-active PCLs). $2{ }^{4}$ Because of the inherent photochemical properties of azo-aromatic compounds, ${ }^{13}$ this imposes a severe limitation to most PCLs developed to date for GluRs5 $5^{-11}$ (and other receptors2): they are active in the dark, where they lie in the more stable trans state. Consequently, these compounds elicit strong tonic responses
ABSTRACT: Photoswitchable neurotransmitters of ionotropic kainate receptors were synthesized by tethering a glutamate moiety to disubstituted C2-bridged azobenzenes, which were prepared through a novel methodology that allows access to diazocines with higher yields and versatility. Because of the singular properties of these photochromes, photoisomerizable compounds were obtained with larger thermal stability for their inert cis isomer than for their biologically activity trans state. This enabled selective neuronal firing upon irradiation without background activity in the dark.

in the absence of illumination (e.g. when acting as receptor agonists), which drastically hampers their use. This is the case of GluAzo (Figure 1a), which is a trans-active, trans-stable partial agonist of ionotropic kainate receptors GluK1 and GluK2, ${ }^{5,14,15}$ two of the principal GluRs mediating excitatory neurotransmission in the central nervous system. 3

To overcome this obstacle while preserving the main design principles behind azo-based PCLs, bridged azobenzenes (brAzo) such as diazocines (C2 bridge, Figure 1b) could be used as photochromes, since they (a) should also favor transactive behavior by switching between extended trans and bent cis configurations, but (b) exhibit cis thermal stability. ${ }^{16-23}$ This combination of properties should therefore allow direct administration of the inert cis form of the PCL, which could then be selectively photoactivated. In addition, diazocines isomerize with visible light, ${ }^{16-23}$ which is a further advantage with respect to common UV-responding azoaromatic compounds. ${ }^{13}$ However, the limited synthetic accessibility and versatility of these photochromes has so far limited their application to the photocontrol of biological systems. ${ }^{22,23 \mathrm{~b}}$ Actually, their use in photopharmacology to modulate the activity of $N$-methyl-D-aspartate (NMDA) receptors and potassium ion channels has only been reported very recently, ${ }^{24}$ for which a low-yield 4-mono-substituted diazocine previously described was employed. ${ }^{23}$ 
a)

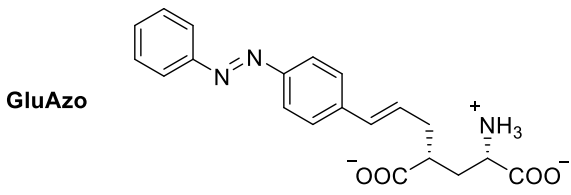

b)

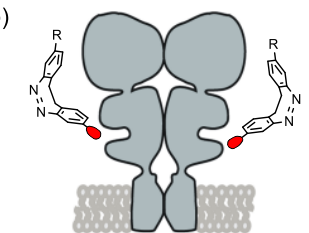

vis $\downarrow \uparrow$ vis or $\Delta$

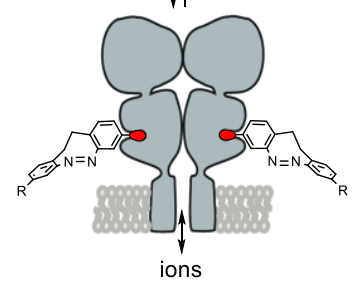

c)
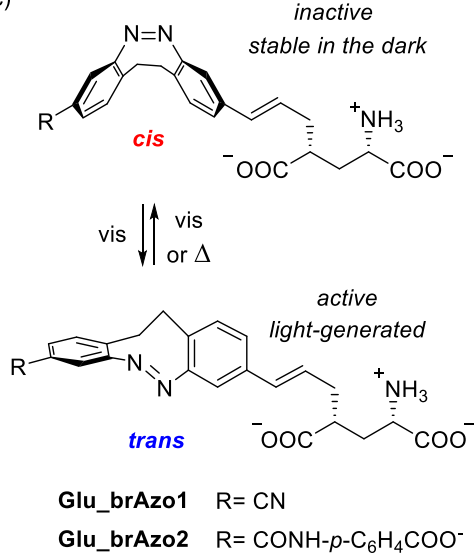

Figure 1. (a) Structure of GluAzo.5 (b) Strategy proposed to prepare trans-active, cis-stable PCLs based on C2-bridged azobenzenes for the light-control of neuronal membrane receptors GluK1 and GluK2. (b) Photoisomerization of Glu_brAzo1-2.

In this work we aim to apply this strategy to photocontrol GluK1 and GluK2, while broadening its scope by developing diazocine-based PCLs with larger yields and multiple functionalization sites to favor chemical versatility. To reach this goal our attention focused on 3,3'-disubstituted diazocines, ${ }^{17,18,21}$ because very inefficient syntheses have been reported to date for 4,4'-disubstituted analogues $\left(<1 \%\right.$ yield $\left.^{22}\right)$. Based on these photochromes and the structure of GluAzo, ${ }^{5}$ we designed Glu_brAzo2 as the first trans-active, cis-stable agonist of GluK1 and GluK2 by tethering a diazocine unit to a biologically active glutamate moiety through a vinyl linker (Figure 1c). In addition, we took advantage of the disubstitution pattern of the photochrome to introduce a lateral ionic, bulky group for (a) enhancing solubility in aqueous media, and (b) further hindering the interaction of the cis isomer with the receptor by increasing the steric congestion around the glutamate moiety. The latter should boost the difference in activity between the two states of the PCL, a required feature given the moderate photoconversions of most functionalized diazocines. ${ }^{17,18,20-23}$ To evaluate this effect, Glu_brAzo1 lacking the additional bulky substituent was also synthesized (Figure 1c).

To validate our design principles, we conducted molecular docking simulations for the two isomers of Glu_brAzo1-2 on kainate receptors. Our attention particularly focused on GluK2, since (a) it presents a narrower binding cavity that imposes larger steric constraints to ligands, ${ }^{25}$ and (b) the crystallographic structure of its ligand-binding domain after complexation with trans-GluAzo is available. ${ }^{15}$ Dockings were computed on this structure keeping the protein rigid, while the initial geometries of the PCLs were optimized at the B3LYP/6-31G(d) level. In all the cases, the best docking solutions placed the glutamate moiety of the ligands in a very similar position as with trans-GluAzo ${ }^{26}$ thus suggesting analogous interaction with the receptor via hydrogen bonds. However, clear differences were observed for the binding arrangement of each ligand (Figure 2 and S1), which led to different complexation energies (in Chemscore units ${ }^{27}$ ): 41.2, 37.0, 48.0, 37.3 for trans-Glu_brAzo1, cis-Glu_brAzo1, transGlu_brAzo2 and cis-Glu_brAzo2 respectively. Importantly, these figures indicate larger affinity of the trans isomers of Glu_brAzo1-2 to GluK2, thus preserving the targeted transactive behavior of GluAzo. By contrast, they do not support our hypothesis that the introduction of an ionic, bulky group in Glu_brAzo2 should decrease the binding efficiency of the cis isomer with respect to less hindered Glu_brAzo1. It must be noted, however, that this is compensated by the higher complexation energy calculated for trans-Glu_brAzo2 relative to trans-Glu_brAzo1, which arises from the additional attractive hydrogen bonding and lipophilic interactions formed between its bulky group and the receptor. Therefore, an enhanced contrast in biological activity is indeed to be expected between the two states of Glu_brAzo2, as originally designed.

Based on our experience in the synthesis of C2-bridged azobenzenes $^{16-21}$ and light-responsive glutamate ligands, ${ }^{28-30}$ we devised a linear sequence to prepare Glu_brAzo1-2 by Heck coupling reaction between their constituting units: a 3,3'disubstituted diazocine and previously reported, protected glutamate derivative $\mathbf{1}^{29}$ (Scheme 1). The preparation of the photochromic unit started from commercially available 4bromo-2-nitrotoluene, $\mathbf{3}$, which was subjected to deprotonation with potassium tert-butoxide and further oxidation with bromine to afford dinitro derivative 4 . When attempting common reductive ring-closing conditions on this intermediate that had been previously reported for the synthesis of diazocines (e.g. $\left.\mathrm{Zn}, \mathrm{Ba}(\mathrm{OH})_{2}\right),{ }^{16-21}$ formation of the desired bridged azobenzene was only observed with very low yields $(<14 \%)$. This prompted us to develop a new methodology for the azocyclization process, for which we explored Mills coupling reaction. With this aim, we first reduced the nitro groups of 4 using sodium sulphide, ${ }^{31}$ which delivered diamine 5 in $90 \%$ yield. Then, oxidative coupling of $\mathbf{5}$ was undertaken in the presence of Oxone ${ }^{\circledR 3} 2$ in glacial acetic acid $^{33}$ at room temperature for $1 \mathrm{~h}$, which nicely furnished dibromosubstituted diazocine 6 in good yield (40\%). According to this result, Oxone $^{\circledR}$-mediated oxidation of one of the aniline moieties to provide the corresponding nitrosoarene followed by condensation with the other, unaltered aniline emerges as a novel onepot synthesis of diazocines with reproducible yields.

Azobenzene 6 was next monocyanated under standard Rosenmund-von Braun conditions ${ }^{34}$ to obtain common asymmetric diazocine 7 in $78 \%$ yield (based on recovered 6). This

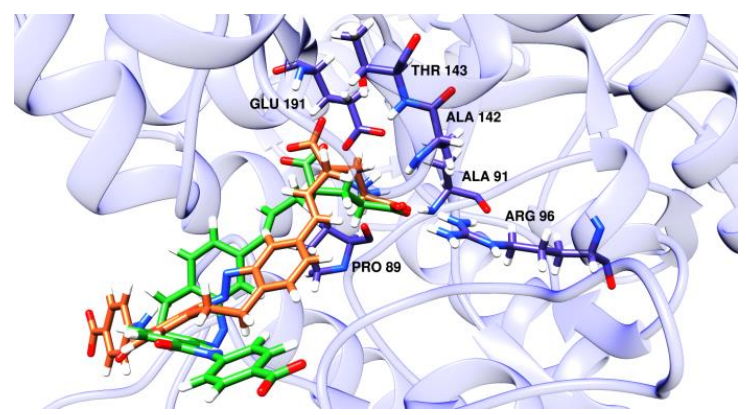

Figure 2. Best docking solutions for trans-Glu_brAzo2 (orange) and cis-Glu_brAzo2 (green) in GluK2. The protein residues interacting with the glutamate group of both ligands are also indicated. Oxygen, nitrogen and hydrogen atoms are depicted in red, blue and white, respectively. 
Scheme 1. Synthesis of Glu_brAzo1 and Glu_brAzo2
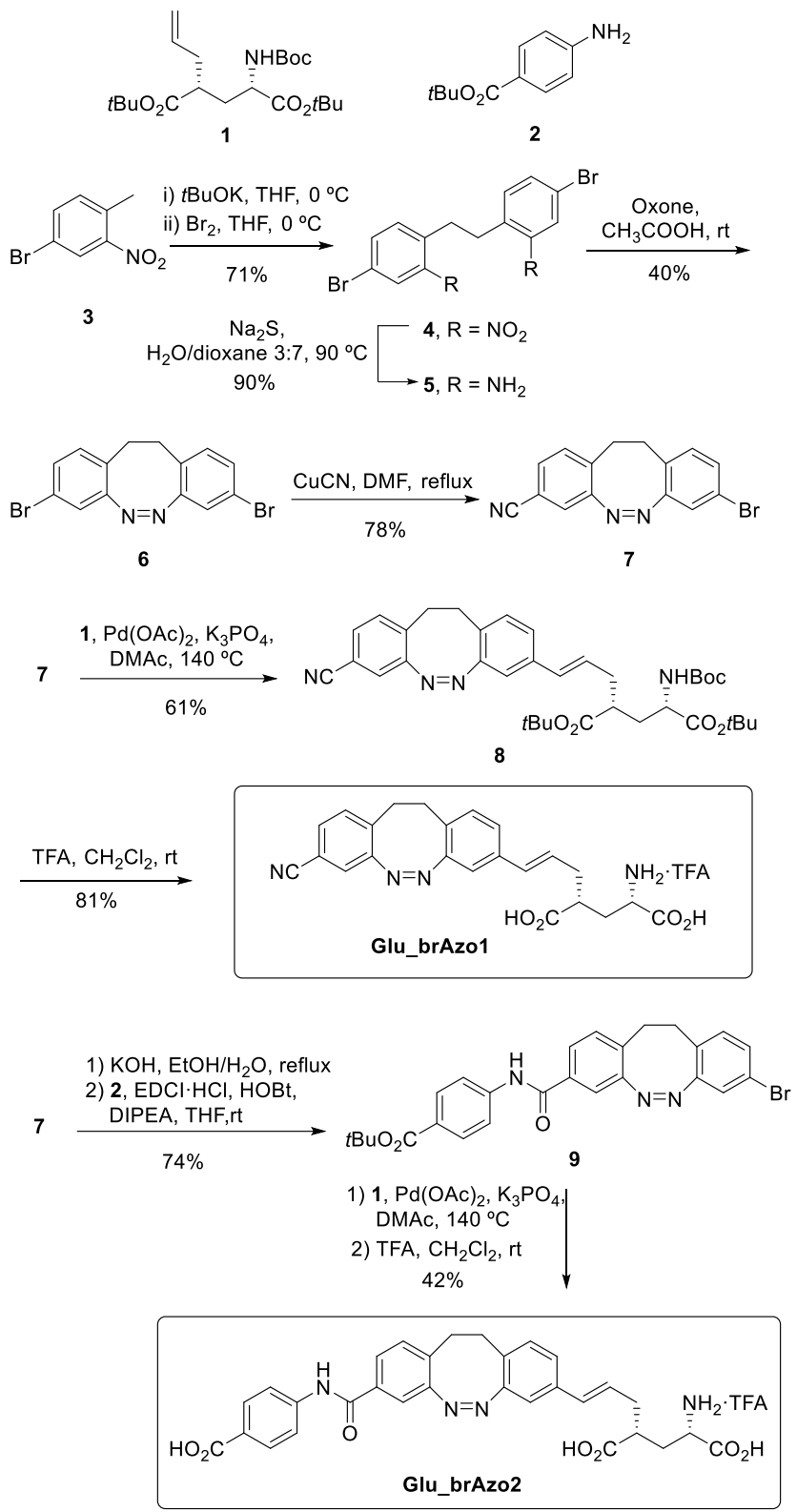

compound was directly coupled to glutamate $\mathbf{1}$ under Palladium catalysis, for which proper selection of the base and the solvent was found to be fundamental. After several tests, the reaction was performed with $\mathrm{K}_{3} \mathrm{PO}_{4}$ and $N, N$ dimethylacetamide ${ }^{35}$ at $140{ }^{\circ} \mathrm{C}$ under argon in the presence of $0.1 \mathrm{~mol} \% \mathrm{Pd}(\mathrm{OAc})_{2}$, which delivered 8 in $61 \%$ yield. Finally, acid removal of the protecting groups gave the target compound Glu_brAzo1 as its monotrifluoroacetate salt in good yield. For Glu_brAzo2, intermediate 7 was hydrolyzed in basic medium to give the corresponding acid, which was then tethered to previously prepared amine 2 using carbodiimide coupling reagent $\mathrm{EDCl} \cdot \mathrm{HCl}$ along with $\mathrm{HOBt}$ to afford 9 in $74 \%$ yield for the two steps. Heck reaction of this compound with 1 under the aforementioned conditions and subsequent removal of the protecting groups finally delivered the target PCL. It must be noted that, despite its larger structural complexity, Glu_brAzo2 was obtained with an overall yield that is ca. 2- to 10-fold larger than those recently reported for diazo- cine-based PCLs, ${ }^{24}$ thus paving the way for the general application of this strategy in photopharmacology.

By comparison with previous data reported for diazocines, ${ }^{16-21}$ NMR and UV-vis absorption analysis confirmed obtainment of the cis isomer of Glu_brAzo1-2 due to their larger stability. In addition, upon irradiation of their $\mathrm{n}-\pi^{*}$ absorption band with violet light $\left(\lambda_{\mathrm{abs}, \max } \sim 395 \mathrm{~nm}, \lambda_{\mathrm{exc}}=405 \mathrm{~nm}\right)$, spectral changes were observed indicative of cis-trans isomerization (Figures $3 \mathrm{a}$ and S2-S4). This is the case of the new red-shifted absorption band found at $\lambda_{\mathrm{abs}, \max } \sim 480 \mathrm{~nm}$, which is distinctive of the trans isomer of diazocines ${ }^{16-18,20-23}$ and allowed reverting the isomerization process by green light illumination $\left(\lambda_{\mathrm{exc}}=532\right.$ $\mathrm{nm}$, Figure 3a and S2-S3 and S5). Further characterization of Glu_brAzo1-2 revealed that they undergo cis-trans photoisomerization with moderate quantum yields $\left(\Phi_{\text {cis-trans }} \sim 0.1\right)$ and efficiencies in aqueous media (Table S1), which resulted in photostationary state mixtures ( $\mathrm{PSS}_{\text {cis-trans }}$ ) containing $47 \%$ and $60 \%$ of their trans isomer, respectively. By contrast, trans-cis photoconversion proceeded quantitatively with high quantum yields ( $\Phi_{\text {trans-cis }} \sim 0.9$ ), thus ensuring fast light-induced recovery of cis-Glu_brAzo1-2 (Table S1) and repetitive photoswitching without degradation (Figure S6). Back-isomerization of the trans state of these compounds was also found to occur in the dark, though at a very much longer time scale $\left(t_{1 / 2} \sim 4 \mathrm{~h}\right.$ at $298 \mathrm{~K}$ in aqueous media, Figure S7 and Table S1).

To assess the capacity of Glu_brAzo1-2 to light-gate GluRs, whole-cell voltage clamp recordings were conducted on HEK293 cells expressing GluK1 or GluK2, whose activation causes channel opening and ion flux across the membrane (Figure 1b).3 ${ }^{5}$ After perfusion of Glu_brAzo1-2, clear changes in the currents evoked in these cells were observed upon irradiation, which were consistent with the different absorption properties of their cis and trans isomers (Figure $3 \mathrm{~b}$ and S8$\mathrm{S} 10)$. In particular, maximal inward currents arising from
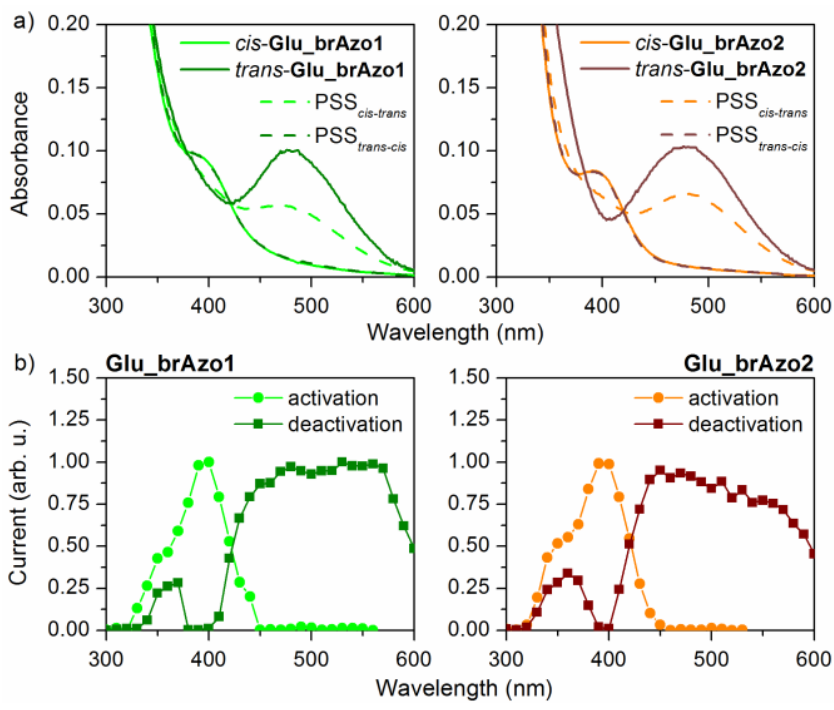

Figure 3. (a) Absorption spectra of both isomers of Glu_brAzo1 and Glu_brAzo2 in PBS:DMSO 1:1, as well as of the PSS mixtures obtained under cis-trans $\left(\lambda_{\mathrm{exc}}=405 \mathrm{~nm}\right)$ and trans-cis $\left(\lambda_{\mathrm{exc}}=\right.$ $532 \mathrm{~nm}$ ) photoisomerization. (b) Activation and deactivation spectra of GluK2 in HEK293 cells after perfusion of Glu_brAzo1 or Glu_brAzo2 and irradiation to induce cis-trans (for activation) and trans-cis (for deactivation) photoisomerization. 


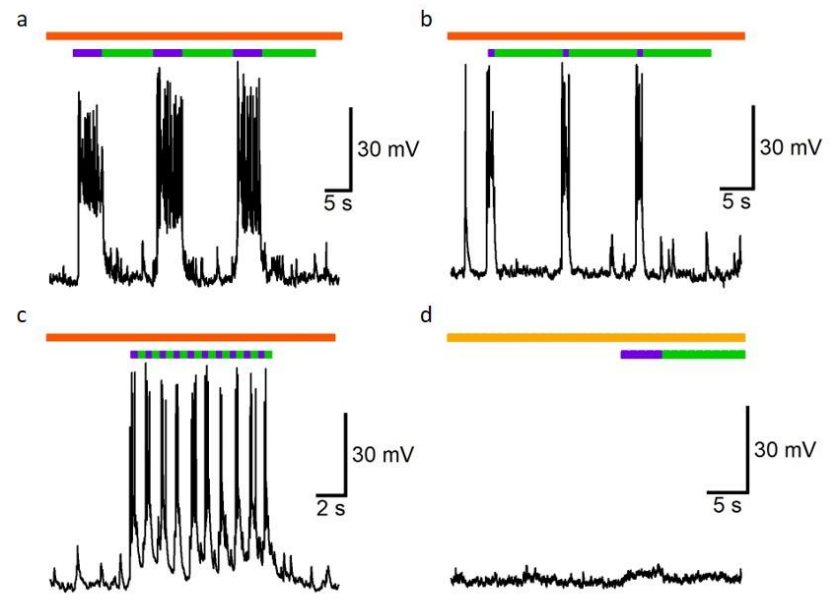

Figure 4. Whole-cell current clamp recordings of rat hippocampal neurons in culture after perfusion of Glu_brAzo2 $(30 \mu \mathrm{M})$ and irradiation at $\lambda_{\text {exc }}=390$ (purple) and $530 \mathrm{~nm}$ (green). Successful neuron activation was observed with $390 \mathrm{~nm}$ light pulses of (a) 5 $\mathrm{s}$, (b) $1 \mathrm{~s}$, and (c) $0.5 \mathrm{~s}$ (1 Hz stimulation), while it was inhibited upon perfusion of DNQX $(10 \mu \mathrm{M})$. Neurons were current clamped at $-60 \mathrm{mV}$ and, to truly report on their GluK2-mediated gating and connectivity, no Concanavalin A was used to prevent receptor desensitization after activation.

receptor activation were measured at $\lambda_{\text {exc }}=390-400 \mathrm{~nm}$ (i.e. when inducing cis-trans photoisomerization of the PCLs). Minimal signals due to receptor deactivation were instead detected in the dark (i.e. for cis-Glu_brAzo1-2) and at $\lambda_{\text {exc }}>$ $450 \mathrm{~nm}$ (i.e. upon trans-cis photoisomerization). As predicted by our molecular docking calculations, preferential interaction between the glutamate agonist ligand and GluK1/GluK2 was therefore observed for the trans state of Glu_brAzo1-2, which allowed light-induced manipulation of these receptors.

The trans-active behavior of Glu_brAzo1-2 was further demonstrated when measuring their dose-response curves with GluK1 and GluK2 in the dark and at $\lambda_{\mathrm{exc}}=390(10-300 \mu \mathrm{M}$, Figure S11). In all the cases, larger inward current signals were retrieved for the PSS $_{\text {cis-trans }}$ mixture generated upon irradiation of the initial cis isomer, though with (a) low-tomoderate photoinduced modulation ( $\mathrm{ca}$. 10-35\% current increase with respect to the dark) and (b) maximal values that were only about $20-40 \%$ of those evoked by free glutamate at $300 \mu \mathrm{M}$. Three main factors should account for these results: incomplete photoconversion into the active trans isomer, as observed in solution $(<60 \%$, Table $\mathrm{S} 1)$; limited modification of the glutamate-binding site affinity upon cis-trans isomerization; and the steric effects imparted by the appended diazocine group with respect to free glutamate even in its less-hindered trans configuration, which are of especial importance for GluK2 interaction owing to its narrower ligand binding cavity. ${ }^{25}$ Actually, the latter accounts for the lower inward current signals with higher light-induced selectivity obtained for this receptor. However, it did not prevent Glu_brAzo2 bearing a bulkier terminal group to (a) show higher activity ( $c a$. 2-fold increase with respect to Glu_brAzo1 for GluK2), as anticipated by our molecular docking simulations, which (b) is further modulated upon photoisomerization, as pursued in our initial design.
Glu_brAzo1-2 were finally tested as photoswitchable neurotransmitters in hippocampal neurons where GluK2 is highly expressed. ${ }^{36}$ Because of their trans-active, cis-stable behavior, physiological behavior was not altered upon perfusion of Glu_brAzo1-2 in the dark, a clear advantage over most PCLs reported for GluRs to date such as GluAzo. $5^{-11}$ Neuronal firing was instead selectively induced upon cis-trans photoisomerization of Glu_brAzo2 at relatively low concentrations (30 $\mu \mathrm{M}$, Figure $4 \mathrm{a}-\mathrm{c})$ and weak light intensities (22.0 and $47.4 \mu \mathrm{W}$ $\mathrm{mm}^{-2}$ at $\lambda_{\mathrm{exc}}=390$ and $530 \mathrm{~nm}$, respectively). As a result, sequential and sustained trains of action potentials could be triggered with Glu_brAzo2 by consecutively switching between violet and green light illumination, even at low irradiation powers and high excitation frequencies (up to $1 \mathrm{~Hz}$, Figure $4 \mathrm{c}$ ). Interestingly, this photoinduced behavior was inhibited by addition of DNQX, ${ }^{37}$ a well-known antagonist of kainate and AMPA GluRs (Figure 4d), which further demonstrates that the efficient photoactivation of hippocampal neurons accomplished with Glu_brAzo2 arose from its lightdependent interaction with GluK2. Noticeably, this clean physiological effect was achieved despite the limited activity modulation measured upon Glu_brAzo2 photoisomerization in GluK2-expressing HEK293 cells (ca. 20\% at $30 \mu \mathrm{M}$ concentration), while it could not be reproduced with the slightly less efficient Glu_brAzo1 agonist (Figure S12). We ascribe this situation to the well-known nonlinear behavior of neuronal signaling, since ligand interaction with a minimum fraction of glutamate receptors is needed to overcome the depolarization threshold required to initiate an action potential.5 In our case, such threshold was only surpassed with transGlu_brAzo2, probably due to its larger affinity for GluK2, as suggested by our measurements in cultured cells.

In conclusion, we demonstrated in this work the potential of C2-bridged azobenzenes for the preparation of azo-based photochromic ligands capable of light-controlling neural receptors, which preserve the larger activity typically observed for their trans state while ensuring larger stability for the inert cis isomer. By introducing a novel synthetic methodology for the preparation of 3,3'-disubstituted diazocines based on an Oxone ${ }^{\circledR}$-mediated intramolecular azocyclization reaction, the desired ligands could be obtained with higher yields and larger versatility, thus enabling fine-tuning of their light-dependent biological response. As a proof of concept, this strategy was applied to the preparation of new photoswitchable neurotransmitters for the light-induced operation of kainate glutamate receptors, with which we achieved selective neural firing upon irradiation without background activity in the dark.

\section{ASSOCIATED CONTENT}

\section{Supporting Information}

The Supporting Information is available free of charge on the ACS Publications website.

General methods and materials, synthetic procedures, and additional computational, photochemical and electrophysiological data (PDF)

\section{AUTHOR INFORMATION}

\section{Corresponding Author}

* pau@icrea.cat (P.G.), jordi.hernando@uab.cat (J.H.)

\section{Author Contributions}


$\$$ These authors contributed equally.

\section{Notes}

The authors declare no competing financial interests.

\section{ACKNOWLEDGMENT}

We acknowledge financial support from MINECO/FEDER (projects CTQ2015-65439-R, CTQ2016-80066-R, CTQ2016-75363-R and CTQ2017-83745-P), AGAUR/Generalitat de Catalunya (CERCA Programme and projects 2017-SGR-00465 and 2017SGR-1442), Human Brain Project WAVESCALES projects, Fundaluce foundation, and Deutsche Forschungsgemeinschaft (SFB677). G. C. acknowledges the Generalitat de Catalunya for her pre-doctoral FI grant. A. G.-C. was supported by fellowship BES-2014-068169.

\section{REFERENCES}

(1) (a) Deisseroth, K. Nat. Methods 2011, 8, 26-29. (b) Deisseroth, K. Nat. Neurosci. 2015, 18, 1213-1225.

(2) (a) Gorostiza, P; Isacoff, E. Y. Science 2008, 322, 395-399. (b) Fehrentz, T.; Schonberger, M.; Trauner, D. Angew. Chem., Int. Ed. 2011, 50, 12156-12182. (c) Kramer, R. H.; Mourot, A.; Adesnik, H. Nat. Neurosci. 2013, 16, 816-823. (d) Velema, W. A.; Szymanski, W.; Feringa, B. L. J. Am. Chem. Soc. 2014, 136, 2178-2191. (e) Berlin, S.; Isacoff, E. Y. EMBO Rep. 2017, 18, 677-692. (f) Hüll, K.; Morstein, J.; Trauner, D. Chem. Rev. 2018, 118, 10710-10747.

(3) (a) Traynelis, S. F.; Wollmuth, L. P.; McBain, C. J.; Menniti, F. S.; Vance, K. M.; Ogden, K. K.; Hansen, K. B.; Yuan, H.; Myers, S. J.; Dingledine, R. Pharmacol. Rev. 2010, 62, 405-496. (b) Niswender, C. M.; Conn, P. J. Annu. Rev. Pharmacol. Toxicol. 2010, 50, 295-322. (c) Bowie, D. CNS Neurol Disord Drug Targets 2008, 7, 129-143.

(4) Reiner, A.; Levitz, J.; Isacoff, E. Y. Curr. Opin. Pharmacol. 2015 $20,135-143$

(5) Volgraf, M.; Gorostiza, P.; Szobota, S.; Helix, M. R.; Isacoff, E. Y.; Trauner, D. J. Am. Chem. Soc. 2007, 129, 260-261.

(6) Stawski, P.; Sumser, M.; Trauner, D. Angew. Chem. Int. Ed. 2012, 51, 5748-5751.

(7) Pittolo, S.; Gómez-Santacana, X.; Eckelt, K.; Rovira, X.; Dalton, J.; Goudet, C.; Pin, J. P.; Llobet, A.; Giraldo, J.; Llebaria, A.; Gorostiza, P. Nat. Chem. Biol. 2014, 10, 813-815.

(8) Rovira, X.; Trapero, A.; Pittolo, S.; Zussy, C.; Faucherre, A.; Jopling, C.; Giraldo, J.; Pin, J.-P.; Gorostiza, P.; Goudet, C.; Llebaria, A. Cell Chem. Biol. 2016, 23, 929-934.

(9) Barber, D. M.; Liu, S. A.; Gottschling, K.; Sumser, M.; Hollmann, M.; Trauner, D. Chem. Sci. 2017, 8, 611-615.

(10) Gómez-Santacana, X.; Pittolo, S.; Rovira, X.; Lopez, M.; Zussy, C.; Dalton, J. A. R.; Faucherre, A.; Jopling, C.; Pin, J.-P.; Ciruela, F.; Goudet, C.; Giraldo, J.; Gorostiza, P.; Llebaria, A. ACS Cent. Sci. 2017, 3, 81-91.

(11) Hartrampf, F. W. W.; Barber, D. M.; Gottshcling, K.; Leippe, P.; Hollmann, M.; Trauner, D. Tetrahedron 2017, 73, 4905-4912.

(12) Laprell, L.; Repak, E.; Franckevicius, V.; Hartrampf, F.; Terhag, J.; Hollmann, M.; Sumser, M.; Rebola, N.; DiGregorio, D. A.; Trauner, D. Nat. Commun. 2015, 6, 8076 .
(13) Bandara, H. M. D.; Burdette, S. C. Chem. Soc. Rev. 2012, 41, $1809-1825$

(14) Abrams, Z. R.; Warrier, A.; Trauner, D.; Zhang, X. Front. Neural Circuits 2010, 4, 13

(15) Reiter, A.; Skerra, A.; Trauner, D.; Schiefner, A. Biochemistry 2013, 52, 8972-8974.

(16) Siewertsen, R.; Neumann, H.; Buchheim-Stehn, B.; Herges, R.; Nather, C.; Renth, F.; Temps, F. J. Am. Chem. Soc. 2009, 131, 15594-15595.

(17) Sell, H.; Nather, C.; Herges, R. Beilstein J. Org. Chem. 2013, 9 , $1-7$

(18) Tellkamp, T.; Shen, J.; Okamoto, Y.; Herges, R. Eur. J. Org. Chem. 2014, 2014, 5456-5461.

(19) Hammerich, M.; Schütt, C.; Stahler, C.; Lentes, P.; Rohricht, F.; Höppner, R.; Herges, R. J. Am. Chem. Soc. 2016, 138, 13111-13114.

(20) Moormann, W.; Langbehn, D.; Herges, R. Synthesis 2017, 49, 3471-3475.

(21) Moormann, W.; Langbehn, D.; Herges, R. Beilstein J. Org. Chem. 2019, 16, 727-732.

(22) Samanta, S.; Qin, C. G.; Lough, A. J.; Woolley, G. A. Angew. Chem. Int. Ed. 2012, 51, 6452-6455.

(23) (a) Joshi, D. K.; Mitchell, M. J.; Bruce, D.; Lough, A. J.; Yan, H. Tetrahedron 2012, 68, 8670-8676. (b) Eljabu, F.; Dhruval, J.; Yan, H. Bioorg. Med. Chem. Lett. 2015, 25, 5594-5596; (c) Jun, M.; Joshi, D. K.; Yalagala, R. S.; Vanloon, J.; Simionescu, R.; Lough, A. J.; Gordon, H. L.; Yan, H. ChemistrySelect 2018, 3, 2697-2701.

(24) Thapaliya, E. R.; Zhao, J.; Ellis-Davies, G. C. R. ACS Chem. Neurosci. 2019, 10.1021/acschemneuro.8b00734

(25) Mayer, M. L. Neuron, 2005, 45, 539-552.

(26) Guo, Y.; Wolter, T.; Kubar, T.; Sumser, M.; Trauner, D.; Elstner, M. PLoS One 2015, 10, e0135399.

(27) Eldridge, M. D.; Murray, C. W.; Auton, T. R.; Paolini, G. V.; Mee, R. P. J. Comput.-Aided Mol. Des. 1997, 11, 425-445..

(28) Izquierdo-Serra, M.; Gascón-Moya, M.; Hirtz, J. J.; Pittolo, S.; Poskanzer, K. E.; Ferrer, Ė.; Alibés, R.; Busqué, F.; Yuste, R.; Hernando, J.; Gorostiza, P. J. Am. Chem. Soc. 2014, 136, 8693-8701.

(29) Gascón-Moya, M.; Pejoan, A.; Izquierdo-Serra, M.; Pittolo, S.; Cabré, G.; Hernando, J.; Alibés, R.; Gorostiza, P.; Busqué, F. J. Org. Chem. 2015, 80, 9915-9925.

(30) Cabré, G.; Garrido-Charles, A.; Moreno, M.; Bosch, M.; Porta-dela-Riva, M.; Krieg, M.; Gascón-Moya, M.; Camarero, N.; Gelabert, R.; Lluch, J. M.; Busqué, F.; Hernando, J.; Gorostiza, P.; Alibés, R. Nat. Commun. 2019, 10, 907.

(31) Mourot, A.; Kienzler, M. A.; Banghart, M. R.; Fehrentz, T.; Huber, F. M. E.; Stein, M.; Kramer, R. H.; Trauner, D. ACS Chem. Neurosci. 2011, 2, 536-543.

(32) Yu, B. C.; Shirai Y.; Tour, J. M. Tetrahedron, 2006, 62, 10303 10310

(33) Davey, H. H.; Lee R. D.; Marks, T. J. J. Org. Chem. 1999, 64, 4976-4979.

(34) Friedman, L.; Shechter, H. J. Org. Chem. 1961, 26, 2522-2524.

(35) Yao, Q.; Kinney, E. P.; Yang, Z. J. Org. Chem. 2003, 68, 75287531.

(36) Carta, M.; Fièvre, S.; Gorlewicz, A.; Mulle, C. Eur. J. Neurosci. 2014, 39, 1835-1844.

(37) Honore, T.; Davies, S. N.; Drejer, J.; Fletcher, E. J.; Jacobsen, P.; Lodge, D.; Nielsen, F. E. Science 1988, 241, 701-703. 